Acta Crystallographica Section B

Structural

Science

ISSN 0108-7681

Editor: Carolyn P. Brock

\title{
Cholesteryl $p$-toluenesulfonate
}

R. J. Chandross and J. Bordner

This electronic document was scanned from an archival copy of material deposited to accompany a paper published in an IUCr journal. In many cases the only accessible copy was a microfilm of a poor-quality original. 


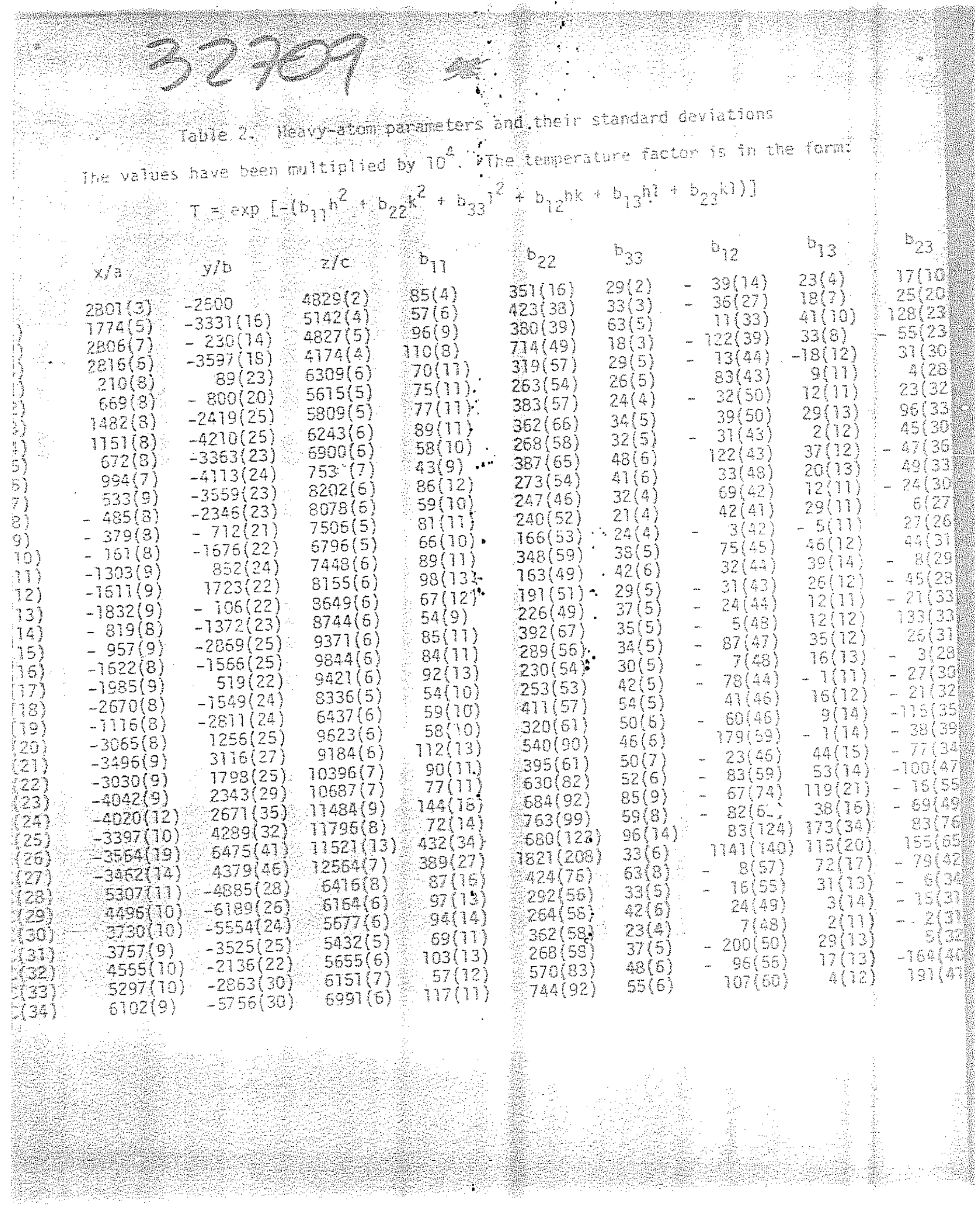




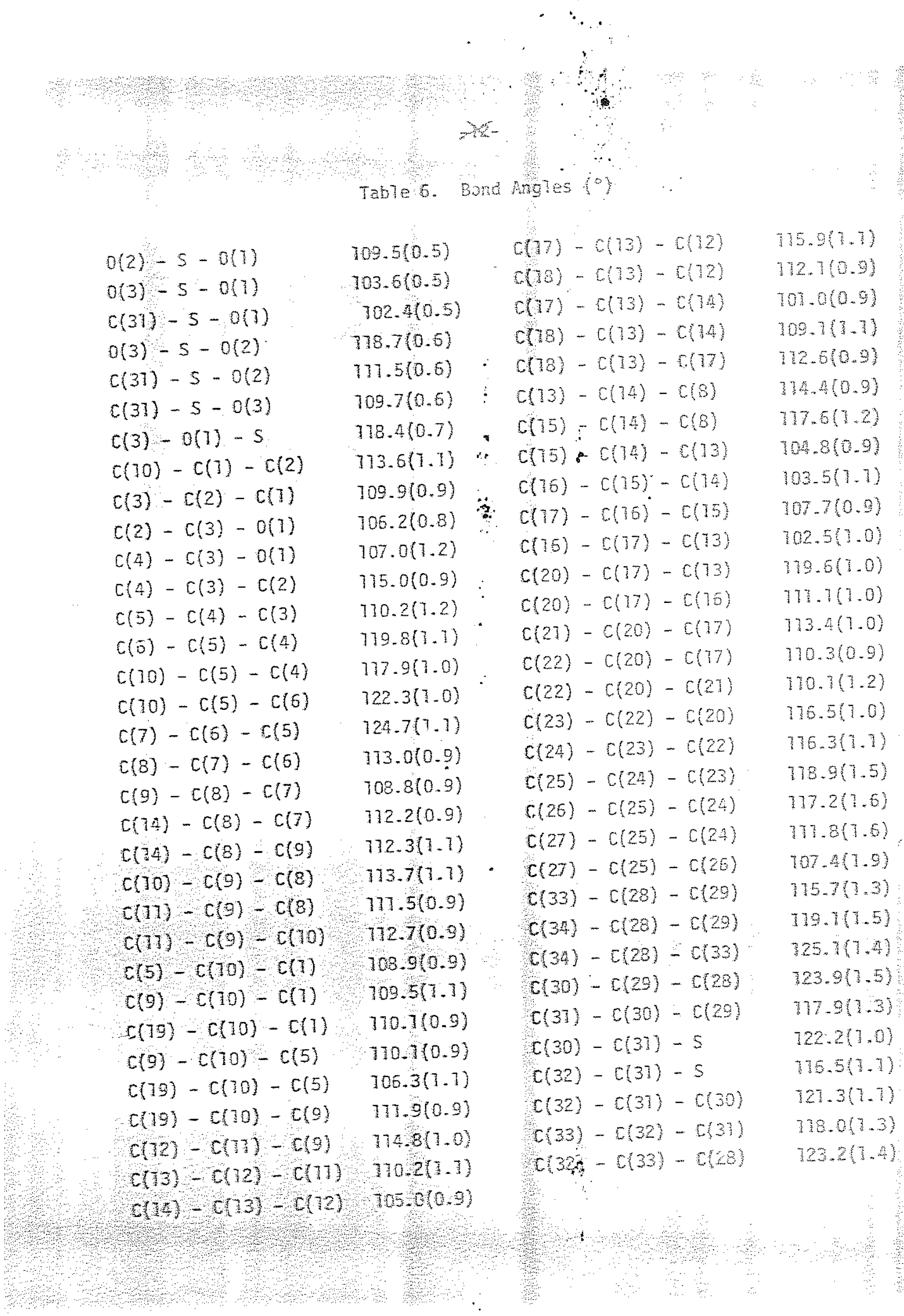



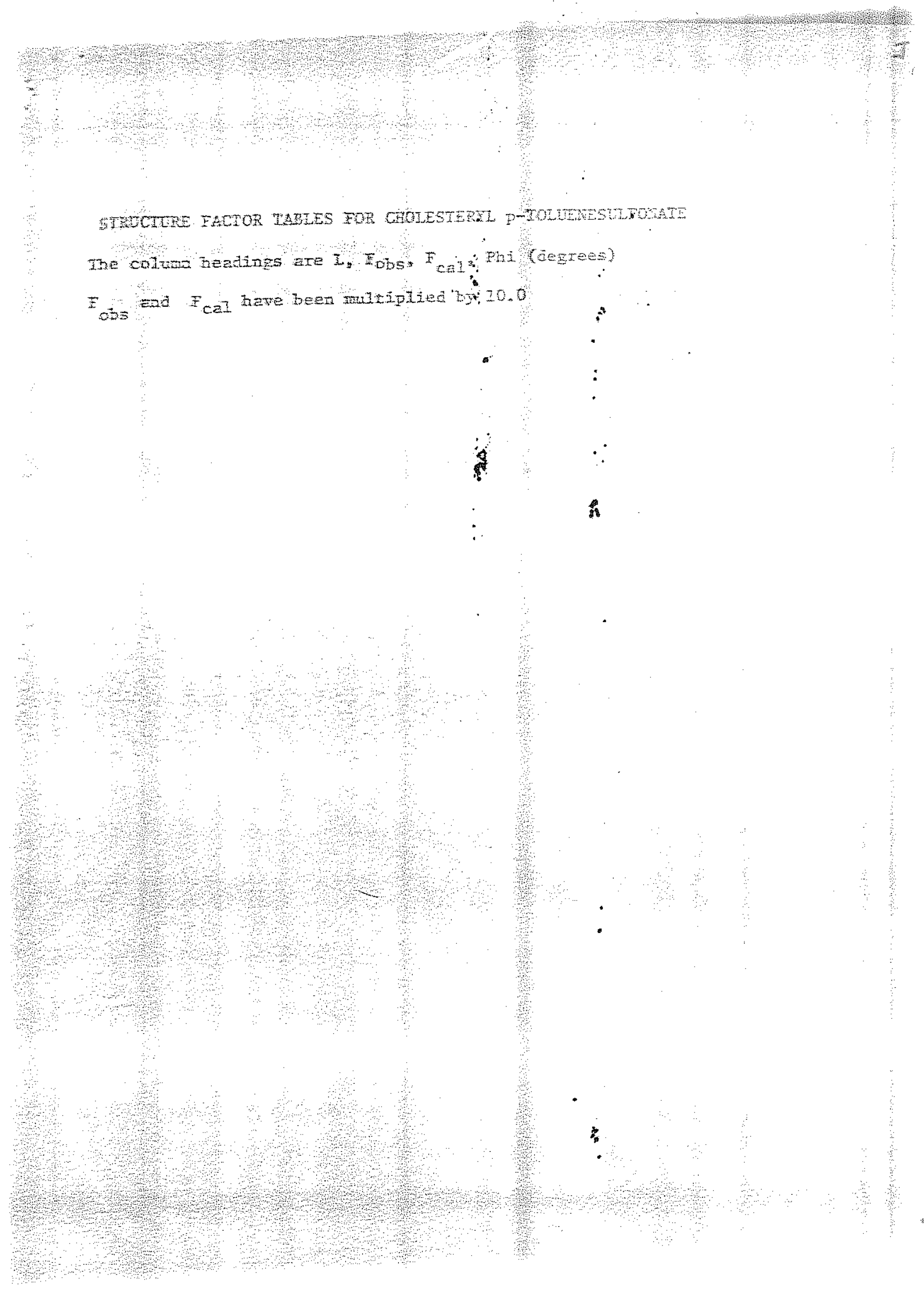


$$
\text { , }
$$$$
8
$$

$$
-3
$$

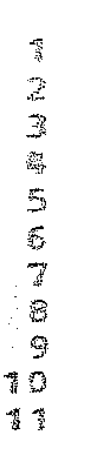$$
\begin{array}{rrrr}
-10 & 0 & 2 & 7 \\
1 & 8 & 9 \\
0 & 2 & -55 * 10
\end{array}
$$$$
\begin{array}{ccccc} 
& 0 & 2 & -55 & 10 \\
2 & 33 & 3 & 3 & 11 \\
3 & 0 & 4 & -175 & 12 \\
7 & 70 & 95 & 2 & 13
\end{array}
$$

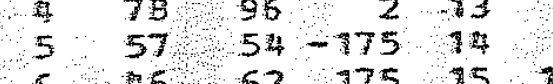$$
78960-77516
$$

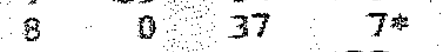$$
9112 \text { 111 }-177
$$

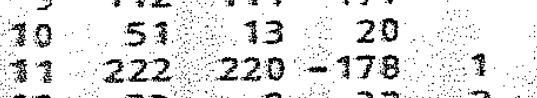

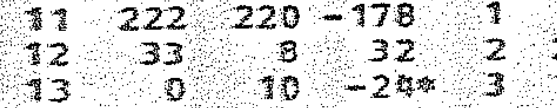$$
-948 \text {, }
$$

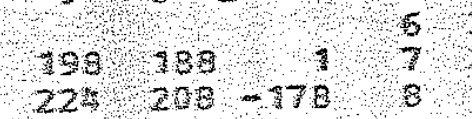

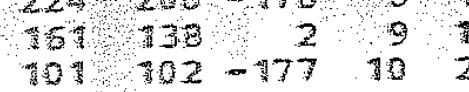$$
4845012211
$$

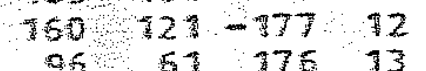

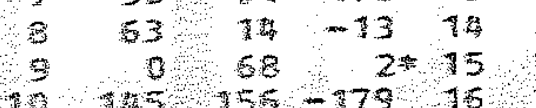$$
\begin{array}{ll}
n \\
m
\end{array}
$$

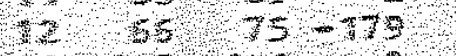

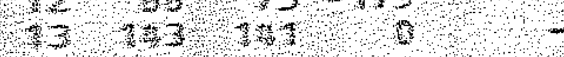

\begin{tabular}{|c|c|c|c|c|c|c|c|c|c|c|}
\hline & & & & & & & & & & \\
\hline & & & 3 & 3 & 62 & $\mathrm{3}$ & 䈉 & 250 & 238 & 2 \\
\hline 0 & 39 & 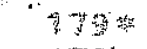 & 准 & 22 & men & $-\frac{1}{3} 8$ & 2 & ens & $7 \mathrm{~B}$ & m- 18 \\
\hline 350 & 169 & -79 & 3 & 8 & 7 桨 & W & 3 & $6 y$ & $7 \%$ & $\mathrm{~b}$ \\
\hline 3. & 9 & 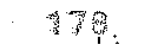 & 5 & gra & 87 & $\operatorname{mon} 1 \frac{1}{2}$ & 彩 & 7 & 75 & nes 5 \\
\hline 257 & 23 & $=-\frac{1}{3}$ & 7 & 128 & .52 & 3 & 5 & 728 & 322 & 拿 \\
\hline 03 & 35 & 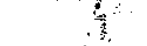 & 8 & 250 & 228 & $-\frac{1}{3} 7$ & 5 & 50 & 35 & ma \\
\hline 9 & 205 & -48 & 9 & 250 & 225 & 2 & 3 & 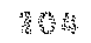 & +2 & 2 \\
\hline 3 & 20 & 2 & 3 & 73 & 9 & -5 & s & 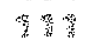 & 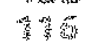 & 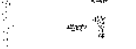 \\
\hline 3 & 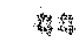 & -6 & $\frac{1}{2}$ & 3 & 9 & 籍 & 战 & 323 & 30 & $\mathrm{~s}$ \\
\hline 20 & $8 ?$ & 3 & 32 & 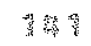 & 帤繁被 & $=\frac{17}{37}$ & 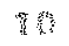 & 32 & 106 & -17 \\
\hline 5 & 5 & -374 & 3 & 255 & 263 & $?$ & $\sqrt{4}+\frac{3}{3}$ & & & 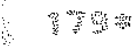 \\
\hline$\$ 59$ & 47 & $\sqrt{3}$ & 笉被 & 33 & 325 & -778 & $\frac{7}{3}$ & W & 2 & 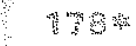 \\
\hline 2 & 55 & -5 & 95 & 355 & 135 & 等 & 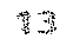 & 32 & 5 & $-x_{n}^{2}$ \\
\hline 28 & 285 & $\frac{7}{8}$ & 霍 & 53 & 76 & onx 175 & 露繁 & $\frac{7+7}{p}$ & 82 & गु \\
\hline 28 & 30 & -17 & 37 & 52 & 32 & 3 & 雾管 & 6 & 900 & $-\frac{1}{3} 3$ \\
\hline 0 & $\therefore 3$ & 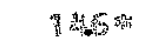 & & & & & $\sqrt{5}$ & 30 残 & 312 & p \\
\hline & & . & & 十该 & $n_{4}^{*}$ & 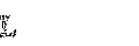 & $\pi$ & 雾 & 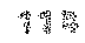 & - 等零是 \\
\hline & 8 & 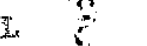 & & & & & 篗 & 23 & $\sqrt[3]{3}$ & พ \\
\hline & & & $\frac{1}{3}$ & P & 73 & - 等7 & & & & \\
\hline 75 & 152 & -177 & 2 & 242 & $26 \%$ & 眥 & & 舟繁 & 整 & Es \\
\hline 372 & 353 & 1 & 3 & 272 & 256 & -3 & & & & \\
\hline 30 & 20 & -15 & 湿 & 317 & De & 77 & 3 & 283 & 290 & $a$ \\
\hline 247 & 252 & 等 & 5 & 283 & 279 & 8 & 2 & 296 & 2018 & -778 \\
\hline 0 & 77 & -154 & 6 & 22 & 23 & 0 & 3 & 250 & 275 & s \\
\hline 236 & 239 & t & 7 & 231 & 240 & 300 & 里 & 587 & 522 & ? \\
\hline 188 & 185 & -777 & 8 & 102 & 93 & 180 & 5 & 52 & 87 & $\Leftrightarrow$ \\
\hline 200 & 193 & 郘 & 9 & 72 & 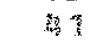 & 178 & 6 & $\frac{1}{148}$ & 396 & -3 \\
\hline$B 9$ & 35 & $-\frac{-276}{4}$ & 0 & 192 & 90 & -1 & 7 & 72 & 59 & 管 \\
\hline 745 & 158 & 3 & 3 & 82 & 32 & 378 & 8 & 52 & 90 & -122 \\
\hline 15 每 & 355 & -379 & 12 & 180 & 377 & -179 & g & 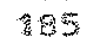 & 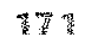 & $\therefore \quad 2$ \\
\hline $10 \%$ & 98 & 3 & 3 & $8 B$ & 90 & 2 & 等踪 & 87 & 霜蔯 & $\operatorname{som} \pi 3$ \\
\hline 90 & 107 & -178 & 14 & 208 & 238 & -770 & 警竞 & a & 等3 & $\quad 3$ \\
\hline as & 5 & 1 & 15 & 133 & 332 & 2 & 霍要 & 72 & 57 & 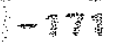 \\
\hline 13 & 99 & -379 & 16 & 130 & 32 & 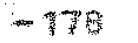 & 3 & 68 & 35 & $4 \mathrm{~T}$ \\
\hline 58 & 82 & 0 & 37 & 72 & 01 & 3 & 霜 & 29 & 253 & $-7 y$ \\
\hline & 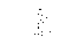 & & 18 & 73 & 53 & -095 & 35 & 55 & 35 & 2 \\
\hline & 0 & I. & & & & & 6 & 50 & 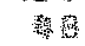 & $-m$ \\
\hline & & & & -3 & 2 & L. & 37 & 152 & 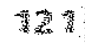 & 2 \\
\hline 52 & $\$ 0$ & 175 & & & & & 蜖 & . & & 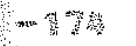 \\
\hline 273 & 195 & t & 糙. & 231 & 226 & $-\frac{6}{3}$ & & & & \\
\hline 305 & 108 & 175 & 2 & 30 & 3 & $3 \quad 3$ & & 酄 & 4 & ter \\
\hline 313 & 316 & 9 & 3 & 37 & की 6 & on & . & a & 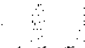 & \\
\hline 87 & 90 & 6 & 4 & 919 & 25 & & 2 & -3 & 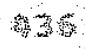 & 蒗 \\
\hline 216 & 21 & 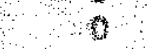 & 5 & 5 & 30 & - & 3 & 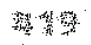 & and & 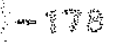 \\
\hline 215 & 23 & -479 & 6 & 33 & 37 & - & 䋣 & 58 & 87 & का \\
\hline 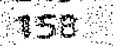 & 30 & 霍 & 4 & 20 & 233 & $-\frac{\pi}{2}$ & 3 & 422 & 雪雾占 & var 5 \\
\hline 46 & 79 & -178 & 8 & 35 & 3 & $\therefore \quad 7$ & 6 & $\sqrt{1}+5$ & 155 & 2 \\
\hline $23 \frac{1}{6}$ & 207 & 翟 & 9 & 305 & 50 & 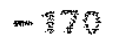 & 7 & 笨可幽 & 35 & 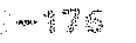 \\
\hline$\therefore 0$ & s & -300 & 30 & 78 & 7 等 & $\bar{z}$ & 列 & 3 & 27 & 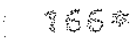 \\
\hline 70 & 59 & 磷 & 3 & 8 & 7 & -28 क & 3 & 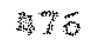 & 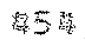 & 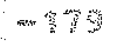 \\
\hline 880 & 90 & -178 & 22 & $7 \mathrm{~m}$ & 3 & 2 & 零 & 霜慜 & 585 & ( \\
\hline 0 & 43 & 6 & 3 & 8 & 99 & -175 & $\hat{t}$ & 5 & 5 & 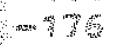 \\
\hline 135 & 37 & -177 & 14 & 45 & 45 & 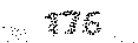 & $\frac{2}{3}$ & 132 & 30 & s \\
\hline 101 & $9^{4}$ & 3 & 15 & 2 & 123 & -75 & 3 & (2) & 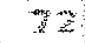 & $\operatorname{mon} \frac{9}{3}$ \\
\hline$\infty$ & 8 & -775 & 15 & 7 & 32 & 83 & a & s & 珽: & 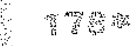 \\
\hline & & & 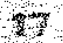 & 31 & 80 & m & n & का & 0 & $\sqrt{7}$ \\
\hline & (4) & 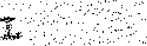 & 18 : & 3 & 露管 & un & एक & trats & $\mathrm{sen}^{2} \mathrm{n}$ & 部 \\
\hline & & & & & & & 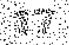 & & & \\
\hline & & 4 & & -2 & n & & tas & 32 & $y$ & $\operatorname{man} 4$ \\
\hline & & & & & & & & & & \\
\hline
\end{tabular}$$
\text { (1) }
$$ 


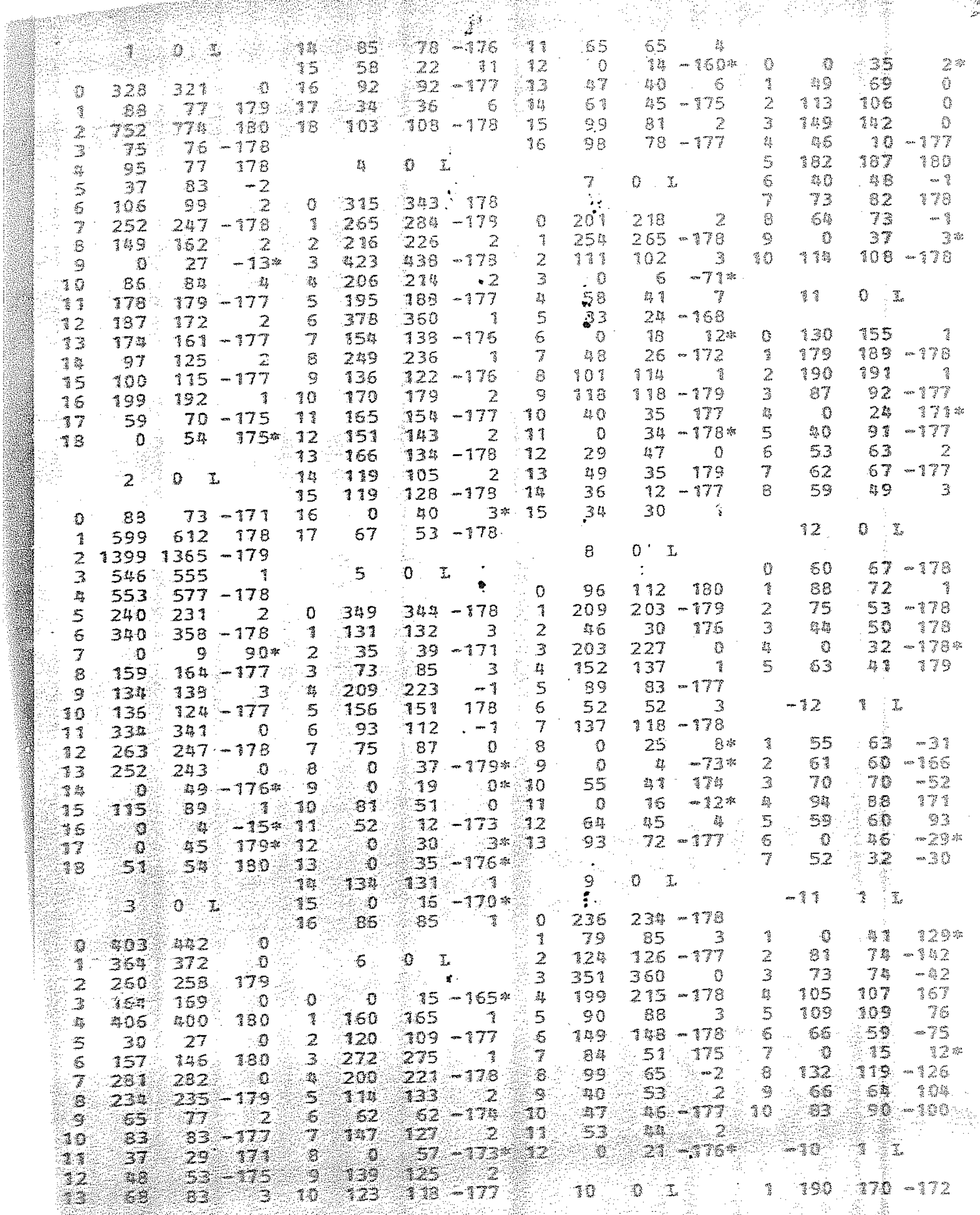




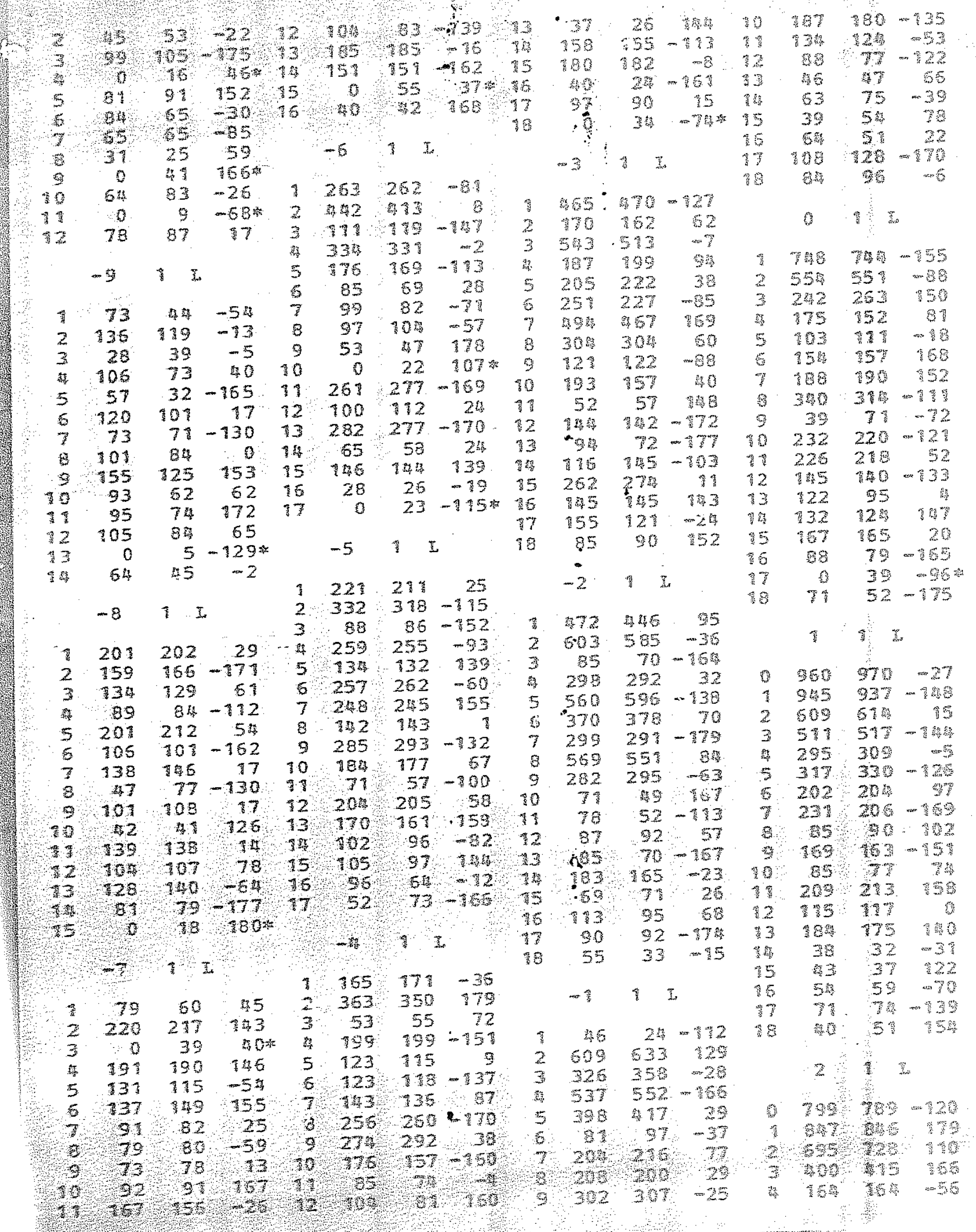




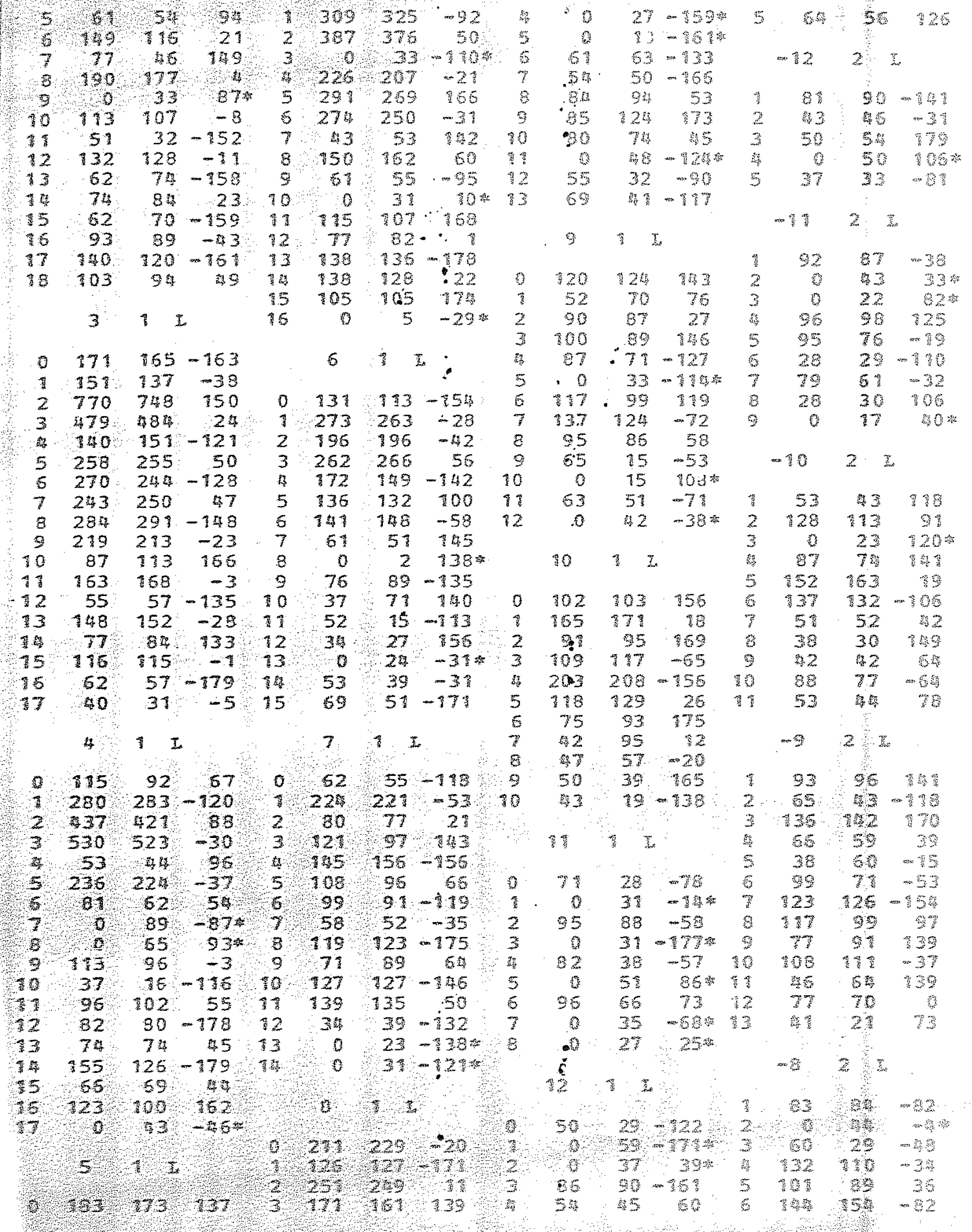




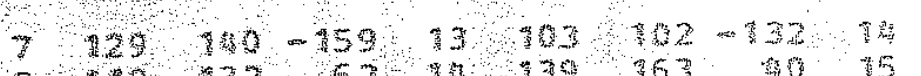

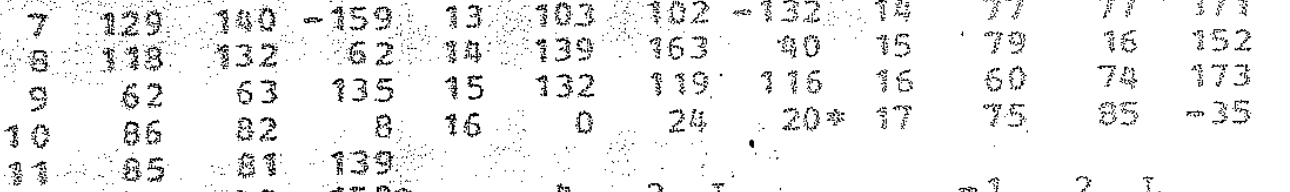

$\begin{array}{rrrr}12 & 0 & 3 & -150 \\ 13 & 70 & \text { is } & -167\end{array}$

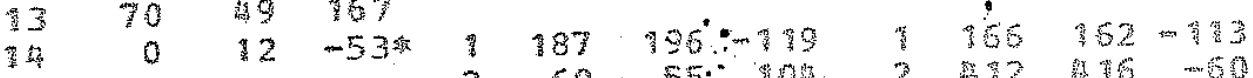

\section{$-72 \pi$}

(3)

$$
5
$$

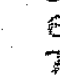$$
\text { (3) }
$$$$
30
$$

10

$\sqrt{3}$

1

3

is 


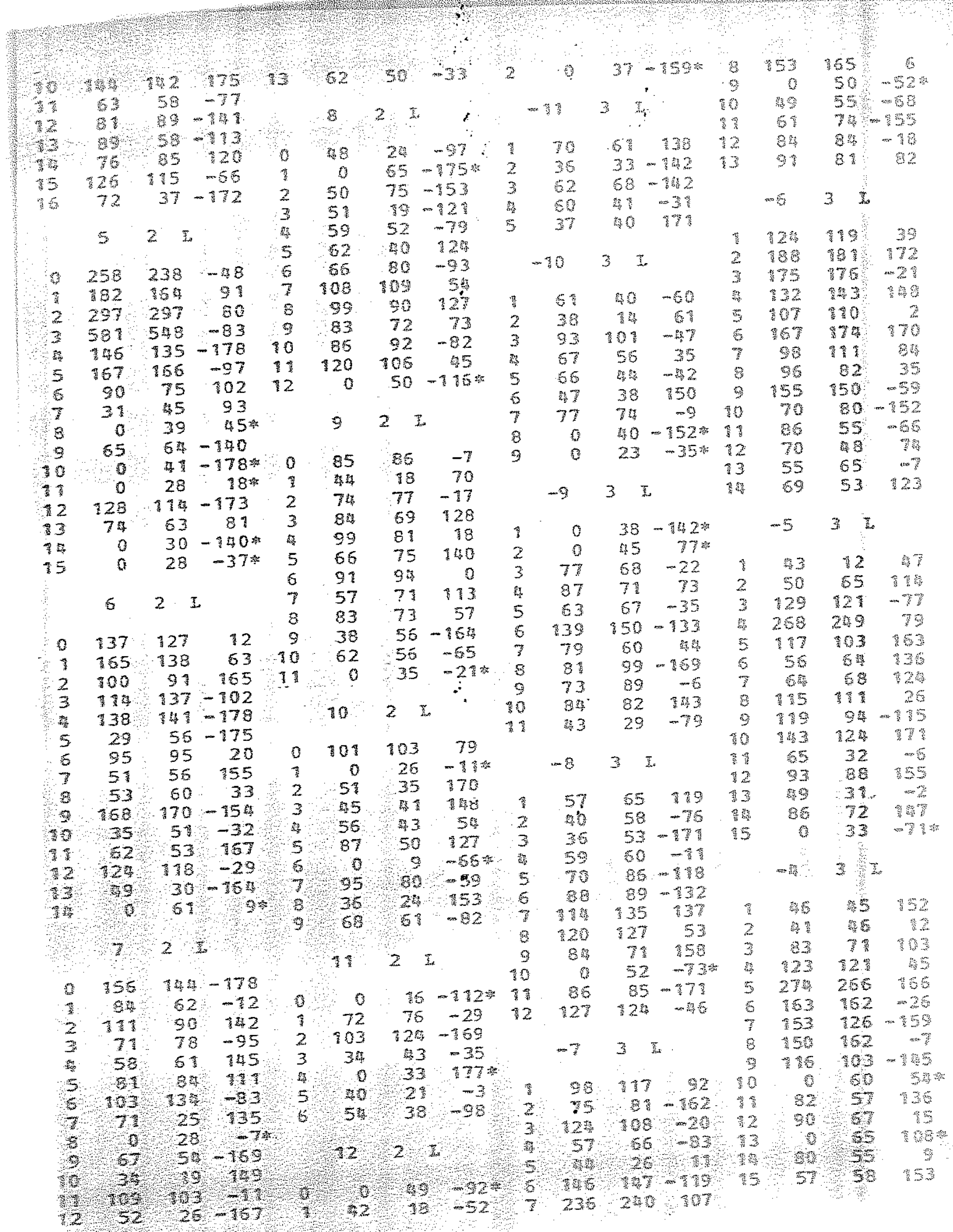




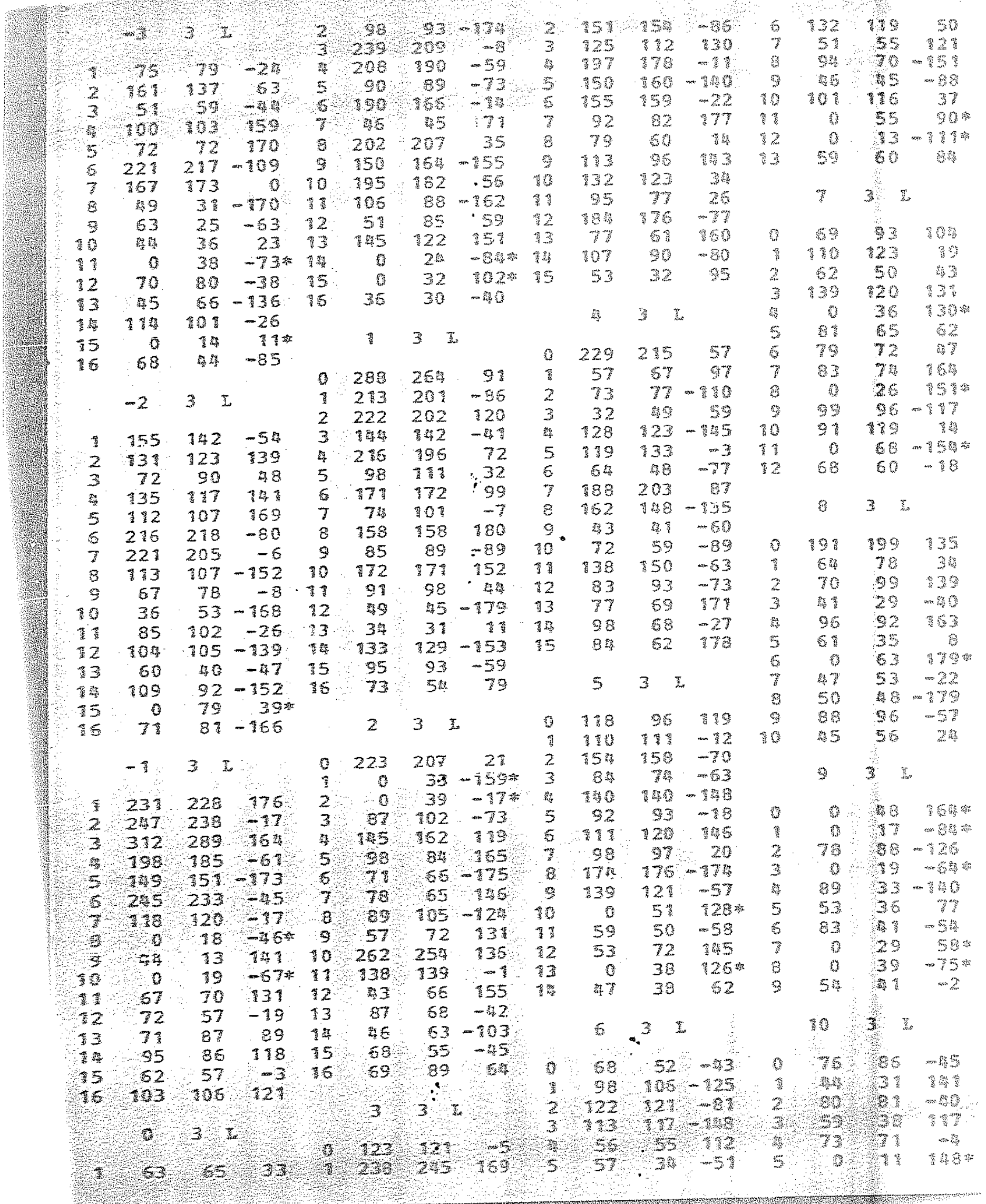




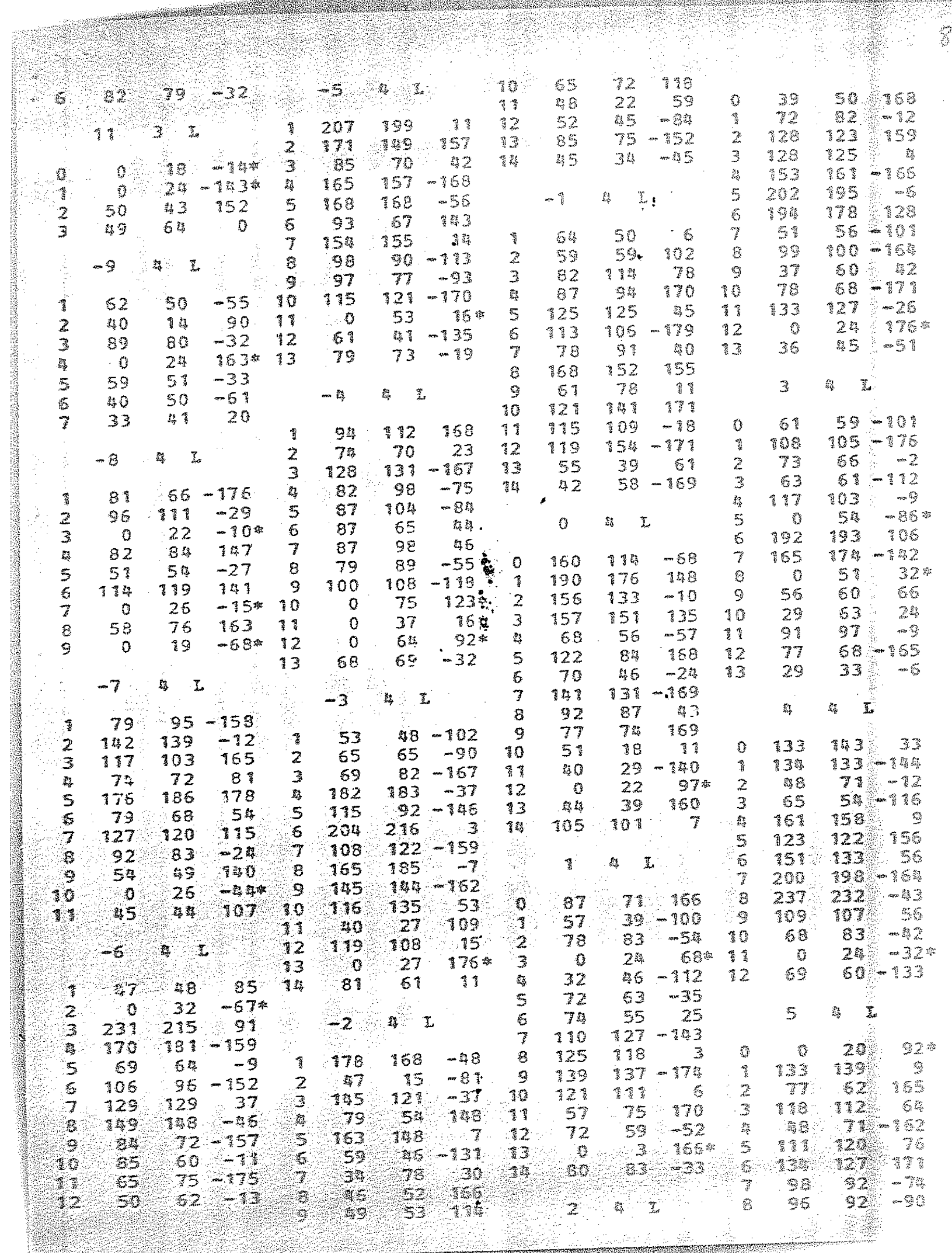




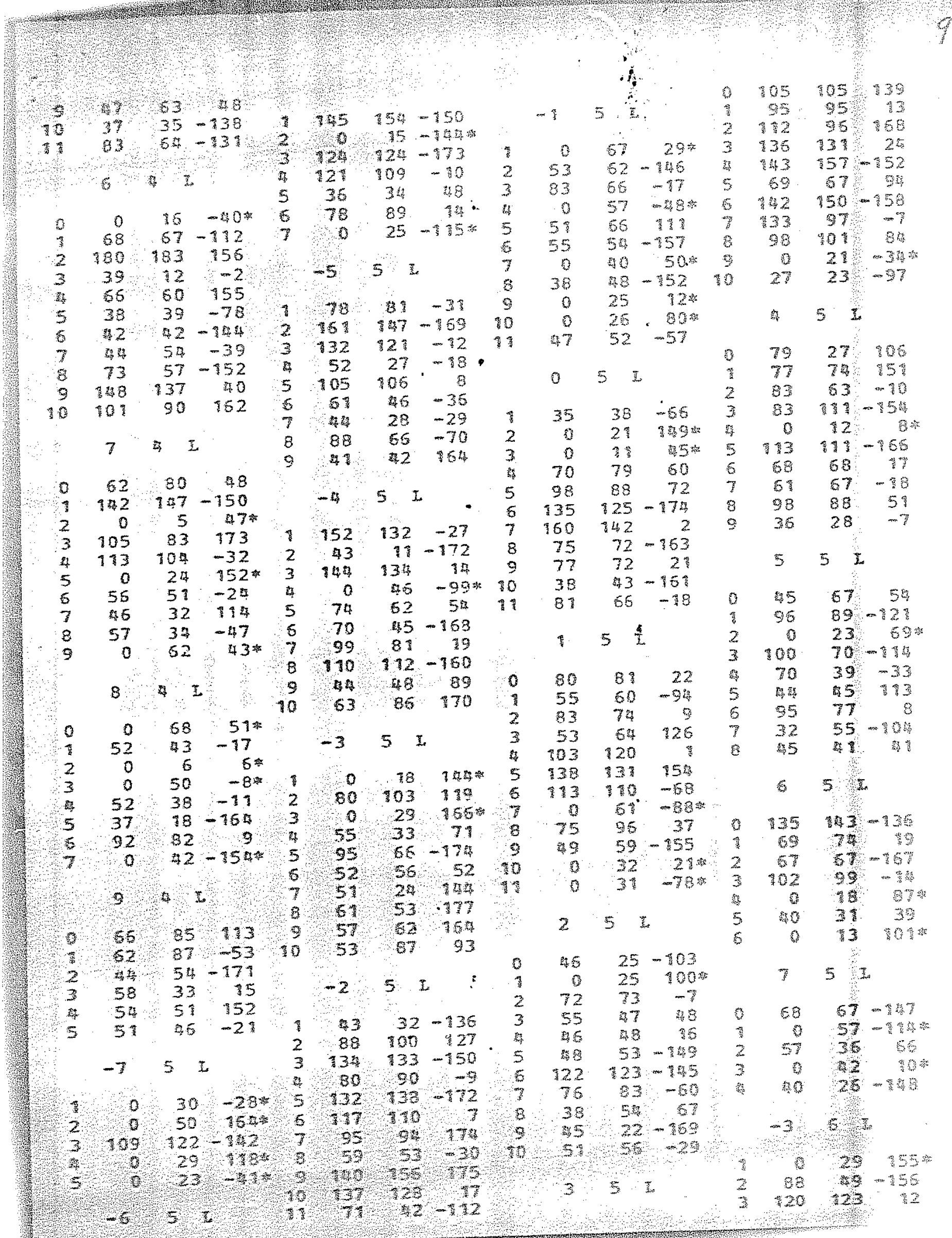




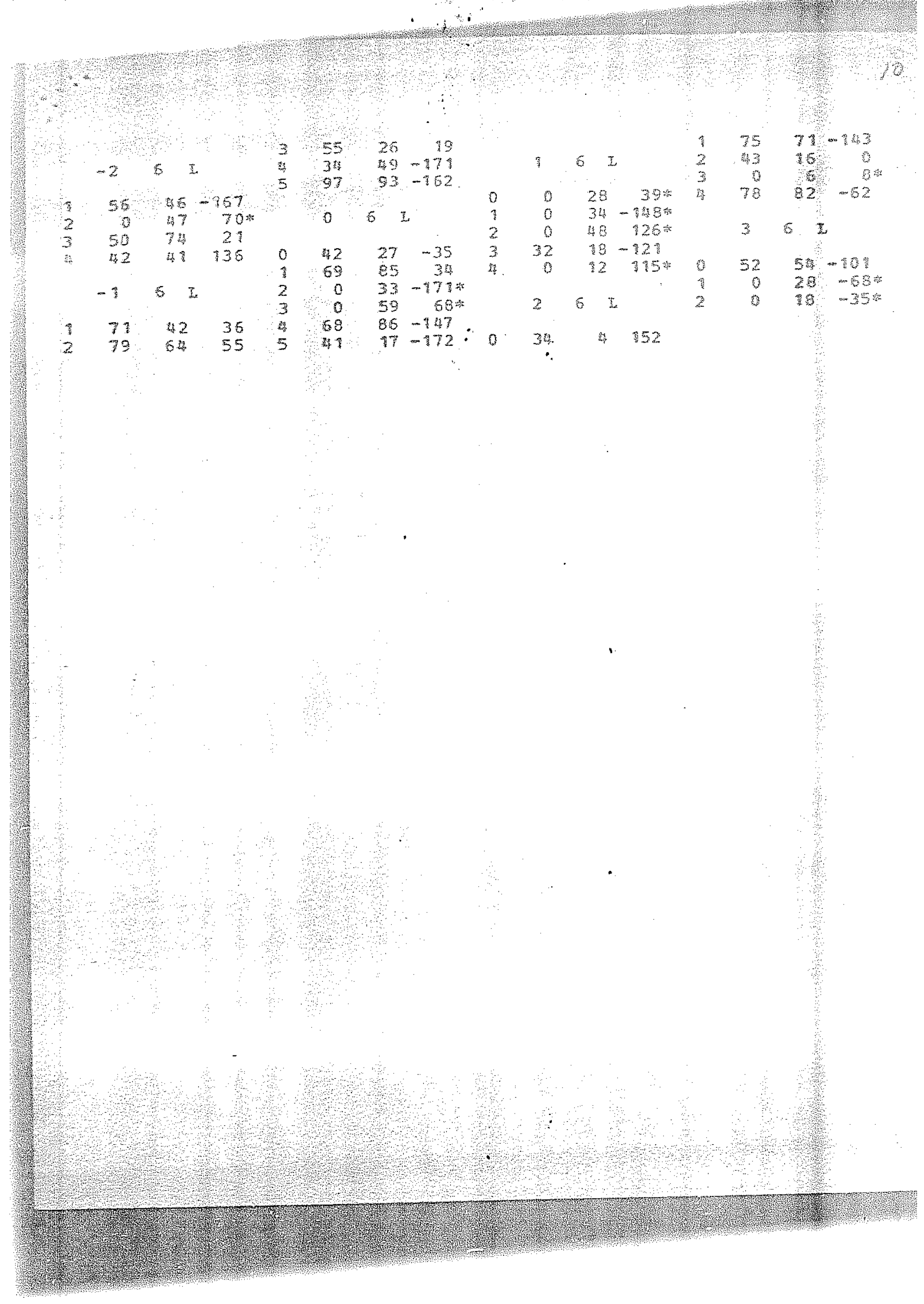

